\title{
Transatlantica
}

Revue d'études américaines. American Studies Journal

\section{Henry D. Thoreau. Wild Apples and Other Natural} History Essays.

William Rossi, ed. Athens : U of Georgia P, 2002. XXVII + 236 p.

\section{Michel Granger}

\section{(2) OpenEdition}

\section{Journals}

Édition électronique

URL : http://journals.openedition.org/transatlantica/741

DOI : $10.4000 /$ transatlantica.741

ISSN : 1765-2766

Éditeur

AFEA

Référence électronique

Michel Granger, "Henry D. Thoreau. Wild Apples and Other Natural History Essays. », Transatlantica [En ligne], 1 | 2003, mis en ligne le 05 avril 2006, consulté le 29 avril 2021. URL : http://

journals.openedition.org/transatlantica/741 ; DOI : https://doi.org/10.4000/transatlantica.741

Ce document a été généré automatiquement le 29 avril 2021.

\section{c) (i) $\Theta$}

Transatlantica - Revue d'études américaines est mis à disposition selon les termes de la licence Creative Commons Attribution - Pas d'Utilisation Commerciale - Pas de Modification 4.0 International. 


\section{Henry D. Thoreau. Wild Apples and Other Natural History Essays.}

William Rossi, ed. Athens : U of Georgia P, 2002. XXVII + 236 p.

\section{Michel Granger}

1 Ce recueil inclut les divers essais que Thoreau a consacrés à la nature pendant une vingtaine d'années et qui ont été publiés précédemment sous le titre inexact d'Excursions (1962) : « Natural History of Massachusetts », «A Walk to Wachusett », « A Winter Walk», "Walking», "The Succession of Forest Trees ", "Autumnal Tints ", "Wild Apples»; il ajoute «Huckleberrie», projet de conférence tardif, publié seulement en 1970. Le texte a été soigneusement mis au point par William Rossi, l'un des membres de l'équipe qui prépare l'édition de référence des œuvres de Thoreau (Princeton).

2 Les quelque 200 pages permettent de se rendre compte du développement de la pensée de Thoreau sur la nature, depuis le point de vue transcendantaliste jusqu'aux travaux les plus scientifiques. On trouve aussi des écrits à finalité plus littéraire dans lesquels l'enjeu consiste à rendre compte de l'expérience de la nature, à tenter de faire vivre cette dernière sur le papier, mais aussi un texte, le dernier, où se révèle la prise de conscience au sujet de la nécessité de protéger la nature sauvage, à un moment où la Nouvelle-Angleterre se déboisait de façon vertigineuse, s'urbanisait et s'industrialisait.

3 Le volume est précédé d'une solide introduction qui replace judicieusement les essais de Thoreau dans le contexte culturel du milieu du XIXe siècle, les situe par rapport à la pensée d'Emerson, explique l'engouement de toute une société pour les diverses sciences de la nature. Ce tableau permet de mieux comprendre qu'il y avait un public pour accueillir les travaux des naturalistes, professionnels ou amateurs, mais aussi les écrits des observateurs passionnés de la nature. 
INDEX

Thèmes : Recensions

\section{AUTEUR}

MICHEL GRANGER

Université Lumière - Lyon 2 